\title{
Pythagorean fuzzy set and its application in career placements based on academic performance using max-min-max composition
}

\author{
Paul Augustine Ejegwa ${ }^{1}$
}

Received: 22 August 2018 / Accepted: 3 January 2019 / Published online: 7 February 2019

(c) The Author(s) 2019

\begin{abstract}
Imprecision is an important factor in any decision-making process. Different tools and approaches have been introduced to handle the imprecise environment of group decision-making. One of the latest tools in dealing with imprecision is Pythagorean fuzzy sets. These sets generalize intuitionistic fuzzy sets with a wider scope of applications, and, thus, the motivation for investigating into its resourcefulness in tackling career placements problem. In this paper, we explore the concept of Pythagorean fuzzy sets and deduce some theorems in connection to score and accuracy functions. Some properties of Pythagorean fuzzy sets are outlined. The idea of relation is established in Pythagorean fuzzy set setting called Pythagorean fuzzy relation with numerical illustrations to validate the developed relation. Finally, a decision-making approach of career placements on the basis of academic performance is presented using the proposed Pythagorean fuzzy relation called max-min-max composition to ascertain the suitability of careers to applicants. The approach adopted in this paper is suggestible to solve the other multi-criteria decision-making problems or multi-attribute decision-making problems, respectively.
\end{abstract}

Keywords Career placements · Fuzzy set · Intuitionistic fuzzy set · Pythagorean fuzzy relation · Pythagorean fuzzy set

\section{Introduction}

Considering the imprecision in decision-making, Zadeh [1] introduced the idea of fuzzy set which has a membership function, $\mu$ that assigns to each element of the universe of discourse, a number from the unit interval $[0,1]$ to indicate the degree of belongingness to the set under consideration. The notion of fuzzy sets generalizes classical sets theory by allowing intermediate situations between the whole and nothing. In a fuzzy set, a membership function is defined to describe the degree of membership of an element to a class. The membership value ranges from 0 to 1 , where 0 shows that the element does not belong to a class, 1 means belongs, and other values indicate the degree of membership to a class. For fuzzy sets, the membership function replaced the characteristic function in crisp sets.

Albeit, the concept of fuzzy sets theory seems to be inconclusive because of the exclusion of nonmembership function and the disregard for the possibility of hesitation margin.

Paul Augustine Ejegwa

ocholohi@gmail.com; ejegwa.augustine@uam.edu.ng

1 Department of Mathematics, Statistics and Computer Science, University of Agriculture, P.M.B. 2373, Makurdi, Nigeria
Atanassov critically studied these shortcomings and proposed a concept called intuitionistic fuzzy sets (IFSs) [2-5]. The construct (that is, IFSs) incorporates both membership function, $\mu$ and nonmembership function, $v$ with hesitation margin, $\pi$ (that is, neither membership nor nonmembership functions), such that $\mu+v \leq 1$ and $\mu+v+\pi=1$. Atanassov [6] introduced intuitionistic fuzzy sets of second type (IFSST) with the property that the sum of the square of the membership and nonmembership degrees is less than or equal to one. This concept generalizes IFSs in a way. The notion of IFSs provides a flexible framework to elaborate uncertainty and vagueness. The idea of IFS seems to be resourceful in modeling many real-life situations like medical diagnosis [7-11], career determination [12], selection process [13], and multi-criteria decision-making [14-16], among others.

There are situations where $\mu+v \geq 1$ unlike the cases capture in IFSs. This limitation in IFS naturally led to a construct, called Pythagorean fuzzy sets (PFSs). Pythagorean fuzzy set (PFS) proposed in [17-19] is a new tool to deal with vagueness considering the membership grade, $\mu$ and nonmembership grade, $v$ satisfying the conditions $\mu+v \leq 1$ or $\mu+v \geq 1$, and also, it follows that $\mu^{2}+v^{2}+\pi^{2}=1$, where $\pi$ is the Pythagorean fuzzy set index. In fact, the ori-

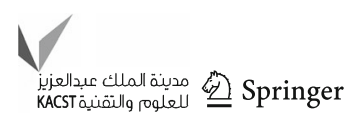


gin of Pythagorean fuzzy sets emanated from IFSST earlier studied in the literature. As a generalized set, PFS has close relationship with IFS. The construct of PFSs can be used to characterize uncertain information more sufficiently and accurately than IFS. Garg [20] presented an improved score function for the ranking order of interval-valued Pythagorean fuzzy sets (IVPFSs). Based on it, a Pythagorean fuzzy technique for order of preference by similarity to ideal solution (TOPSIS) method by taking the preferences of the experts in the form of interval-valued Pythagorean fuzzy decision matrices was discussed. Other explorations of the theory of PFSs can be found in [21-27].

Pythagorean fuzzy set has attracted great attentions of many researchers, and subsequently, the concept has been applied to many application areas such as decision-making, aggregation operators, and information measures. Rahman et al. [28] worked on some geometric aggregation operators on interval-valued PFSs (IVPFSs) and applied same to group decision-making problem. Perez-Dominguez [29] presented a multiobjective optimization on the basis of ratio analysis (MOORA) under PFS setting and applied it to MCDM problem. Liang and $\mathrm{Xu}$ [30] proposed the idea of PFSs in hesitant environment and its MCDM ability by employing TOPSIS using energy project selection model. Mohagheghi et al. [31] offered a novel last aggregation group decision-making process for the weight of decision-makers using PFSs. Rahman et al. [32] proposed some approaches to multi-attribute group decision-making based on induced interval-valued Pythagorean fuzzy Einstein aggregation operator.

Garg $[33,34]$ unveiled some new logarithmic operational laws and their aggregation operator for PFS with some applications and discussed a decision-making problem under Pythagorean fuzzy environment by proposing some generalized aggregation operators. Garg [35] proposed an improved score function for solving MCDM problem with partially known weight information, such that the preferences related to the criteria are taken in the form of interval-valued Pythagorean fuzzy sets. Garg [36,37] developed a new decision-making model with probabilistic information, using the concept of immediate probabilities to aggregate the information under the Pythagorean fuzzy set environment, and defined two new exponential operational laws about IVPFS and their corresponding aggregation operators with application to MCDM. Other applications of PFSs and IVPFSs, respectively, in conjunction to decision-making problems, especially in MCDM and MADM, have been studied in [3851].

In this paper, we are motivated to investigate the resourcefulness of PFSs in tackling career placements problem via max-min-max rule because of its wider scope of applications in real-life problems imbedded with imprecision. The paper is aimed at exploring the notion of PFSs and its application to career placements on the basis of academic per- formance using max-min-max composition. To achieve this aim, we reiterate the concept of PFSs, outline some properties of PFSs, and deduce some theorems with respect to score and accuracy functions studied in the literature hitherto. The idea of Pythagorean fuzzy relation is proposed as an extension of fuzzy relation, as well as intuitionistic fuzzy relation introduced in [8,52], respectively. Conclusively, a new application of Pythagorean fuzzy sets is explicated in career placements on the basis of academic performance using the proposed relation. The rest of the paper are thus presented: Sect. 2 provides some preliminaries on fuzzy sets and IFSs as foundations to the idea of PFSs, while Sect. 3 covers the notion of PFSs with some theorems. We present Pythagorean fuzzy relation and its numerical verifications in Sect. 4. An application of Pythagorean fuzzy relation (maxmin-max composition) is supplied in a hypothetical case study in Sect. 5. Finally, Sect. 6 concludes the paper and provides direction for future studies.

\section{Preliminaries}

We recall some basic notions of fuzzy sets and IFSs.

\section{Fuzzy sets}

Definition 2.1 (See [1]) Let $X$ be a nonempty set. A fuzzy set $A$ in $X$ is characterized by a membership function:

$\mu_{A}: X \rightarrow[0,1]$.

That is:

$\mu_{A}(x)= \begin{cases}1, & \text { if } x \in X \\ 0, & \text { if } x \notin X \\ (0,1) & \text { if } x \text { is partly in } X .\end{cases}$

Alternatively, a fuzzy set $A$ in $X$ is an object having the form

$A=\left\{\left\langle x, \mu_{A}(x)\right\rangle \mid x \in X\right\} \quad$ or $\quad A=\left\{\left\langle\frac{\mu_{A}(x)}{x}\right\rangle \mid x \in X\right\}$,

where the function

$\mu_{A}(x): X \rightarrow[0,1]$

defines the degree of membership of the element, $x \in X$.

The closer the membership value $\mu_{A}(x)$ to 1 , the more $x$ belongs to $A$, where the grades 1 and 0 represent full membership and full nonmembership. Fuzzy set is a collection of objects with graded membership, that is, having degree of membership. Fuzzy set is an extension of the classical notion of set. In classical set theory, the membership of elements in a 
set is assessed in binary terms according to a bivalent condition; an element either belongs or does not belong to the set. Classical bivalent sets are in fuzzy set theory called crisp sets. Fuzzy sets are generalized classical sets, since the indicator function of classical sets is special cases of the membership functions of fuzzy sets, if the latter only take values 0 or 1. Fuzzy sets theory permits the gradual assessment of the membership of element in a set; this is described with the aid of a membership function valued in the real unit interval $[0,1]$.

Let us consider two examples:

(i) all employees of $X Y Z$ who are over $1.8 \mathrm{~m}$ in height;

(ii) all employees of $X Y Z$ who are tall.

The first example is a classical set with a universe (all $X Y Z$ employees) and a membership rule that divides the universe into members (those over $1.8 \mathrm{~m}$ ) and nonmembers. The second example is a fuzzy set, because some employees are definitely in the set and some are definitely not in the set, but some are borderline.

This distinction between the ins, the outs, and the borderline is made more exact by the membership function, $\mu$. If we return to our second example and let $A$ represent the fuzzy set of all tall employees and $x$ represent a member of the universe $X$ (i.e. all employees), then $\mu_{A}(x)$ would be $\mu_{A}(x)=1$ if $x$ is definitely tall or $\mu_{A}(x)=0$ if $x$ is definitely not tall or $0<\mu_{A}(x)<1$ for borderline cases.

\section{Intuitionistic fuzzy sets}

Definition 2.2 (See [2-5]) Let a nonempty set $X$ be fixed. An IFS $A$ in $X$ is an object having the form:

$A=\left\{\left\langle x, \mu_{A}(x), v_{A}(x)\right\rangle \mid x \in X\right\}$

or

$A=\left\{\left\langle\frac{\mu_{A}(x), v_{A}(x)}{x}\right\rangle \mid x \in X\right\}$,

where the functions

$\mu_{A}(x): X \rightarrow[0,1]$ and $v_{A}(x): X \rightarrow[0,1]$

define the degree of membership and the degree of nonmembership, respectively, of the element $x \in X$ to $A$, which is a subset of $X$, and for every $x \in X$ :

$0 \leq \mu_{A}(x)+v_{A}(x) \leq 1$

For each $A$ in $X$ :

$\pi_{A}(x)=1-\mu_{A}(x)-v_{A}(x)$ is the intuitionistic fuzzy set index or hesitation margin of $x$ in $X$. The hesitation margin $\pi_{A}(x)$ is the degree of nondeterminacy of $x \in X$, to the set $A$ and $\pi_{A}(x) \in[0,1]$. The hesitation margin is the function that expresses lack of knowledge of whether $x \in X$ or $x \notin X$. Thus:

$\mu_{A}(x)+v_{A}(x)+\pi_{A}(x)=1$.

Example 2.1 Let $X=\{x, y, z\}$ be a fixed universe of discourse and

$A=\left\{\left\langle\frac{0.6,0.1}{x}\right\rangle,\left\langle\frac{0.8,0.1}{y}\right\rangle,\left\langle\frac{0.5,0.3}{z}\right\rangle\right\}$

be the intuitionistic fuzzy set in $X$. The hesitation margins of the elements $x, y, z$ to $A$ are as follows:

$\pi_{A}(x)=0.3, \pi_{A}(y)=0.1$ and $\pi_{A}(z)=0.2$.

\section{Construct of Pythagorean fuzzy sets}

Definition 3.1 (See [17-19]) Let $X$ be a universal set. Then, a Pythagorean fuzzy set $A$, which is a set of ordered pairs over $X$, is defined by the following:

$A=\left\{\left\langle x, \mu_{A}(x), v_{A}(x)\right\rangle \mid x \in X\right\}$

or

$A=\left\{\left\langle\frac{\mu_{A}(x), v_{A}(x)}{x}\right\rangle \mid x \in X\right\}$,

where the functions

$\mu_{A}(x): X \rightarrow[0,1]$ and $v_{A}(x): X \rightarrow[0,1]$

define the degree of membership and the degree of nonmembership, respectively, of the element $x \in X$ to $A$, which is a subset of $X$, and for every $x \in X$ :

$0 \leq\left(\mu_{A}(x)\right)^{2}+\left(v_{A}(x)\right)^{2} \leq 1$.

Supposing $\left(\mu_{A}(x)\right)^{2}+\left(v_{A}(x)\right)^{2} \leq 1$, then there is a degree of indeterminacy of $x \in X$ to $A$ defined by $\pi_{A}(x)=$ $\sqrt{1-\left[\left(\mu_{A}(x)\right)^{2}+\left(v_{A}(x)\right)^{2}\right]}$ and $\pi_{A}(x) \in[0,1]$. In what follows, $\left(\mu_{A}(x)\right)^{2}+\left(v_{A}(x)\right)^{2}+\left(\pi_{A}(x)\right)^{2}=1$. Otherwise, $\pi_{A}(x)=0$ whenever $\left(\mu_{A}(x)\right)^{2}+\left(v_{A}(x)\right)^{2}=1$.

We denote the set of all PFSs over $X$ by $\operatorname{PFS}(X)$.

Example 3.1 Let $A \in \operatorname{PFS}(X)$. Suppose that $\mu_{A}(x)=0.7$ and $v_{A}(x)=0.5$ for $X=\{x\}$. Clearly, $0.7+0.5 \nless 1$, but $0.7^{2}+0.5^{2} \leq 1$. Thus, $\pi_{A}(x)=0.5099$, and hence, $\left(\mu_{A}(x)\right)^{2}+\left(v_{A}(x)\right)^{2}+\left(\pi_{A}(x)\right)^{2}=1$. 
Table 1 Pythagorean fuzzy sets and intuitionistic fuzzy sets

\begin{tabular}{ll}
\hline Intuitionistic fuzzy sets & Pythagorean fuzzy sets \\
\hline$\mu+v \leq 1$ & $\mu+v \leq 1$ or $\mu+v \geq 1$ \\
$0 \leq \mu+v \leq 1$ & $0 \leq \mu^{2}+v^{2} \leq 1$ \\
$\pi=1-(\mu+v)$ & $\pi=\sqrt{1-\left[\mu^{2}+v^{2}\right]}$ \\
$\mu+v+\pi=1$ & $\mu^{2}+v^{2}+\pi^{2}=1$ \\
\hline
\end{tabular}

Table 1 explains the difference between Pythagorean fuzzy sets and intuitionistic fuzzy sets.

Theorem 3.1 Let $X=\left\{x_{i}\right\}$ be a universal set, for $i=1, \ldots, n$ and $A \in \operatorname{PFS}(X)$. Suppose that $\pi_{A}\left(x_{i}\right)=0$, and then, the following hold:

(i) $\left|\mu_{A}\left(x_{i}\right)\right|=\sqrt{\left|\left(v_{A}\left(x_{i}\right)+1\right)\left(v_{A}\left(x_{i}\right)-1\right)\right|}$.

(ii) $\left|v_{A}\left(x_{i}\right)\right|=\sqrt{\left|\left(\mu_{A}\left(x_{i}\right)+1\right)\left(\mu_{A}\left(x_{i}\right)-1\right)\right|}$.

Proof Suppose that $x_{i} \in X$ and $A \in \operatorname{PFS}(X)$. Then, we prove (i) and (ii). Assume that $\pi_{A}\left(x_{i}\right)=0$ for $x_{i} \in X$ :

(i) we have the following:

$$
\begin{aligned}
& \left(\mu_{A}\left(x_{i}\right)\right)^{2}+\left(v_{A}\left(x_{i}\right)\right)^{2}=1 \Rightarrow-\left(\mu_{A}\left(x_{i}\right)\right)^{2}=\left(v_{A}\left(x_{i}\right)\right)^{2}-1 \\
& \quad \Rightarrow-\left(\mu_{A}\left(x_{i}\right)\right)^{2}=\left(v_{A}\left(x_{i}\right)+1\right)\left(v_{A}\left(x_{i}\right)-1\right) \\
& \quad \Rightarrow\left|\left(\mu_{A}\left(x_{i}\right)\right)^{2}\right|=\left|\left(v_{A}\left(x_{i}\right)+1\right)\left(v_{A}\left(x_{i}\right)-1\right)\right| \\
& \quad \Rightarrow\left|\mu_{A}\left(x_{i}\right)\right|^{2}=\left|\left(v_{A}\left(x_{i}\right)+1\right)\left(v_{A}\left(x_{i}\right)-1\right)\right| \\
& \quad \Rightarrow\left|\mu_{A}\left(x_{i}\right)\right|=\sqrt{\left|\left(v_{A}\left(x_{i}\right)+1\right)\left(v_{A}\left(x_{i}\right)-1\right)\right|} .
\end{aligned}
$$

(ii) Similar to (i).

Example 3.2 Suppose $A \in \operatorname{PFS}(X)$ and $v_{A}\left(x_{i}\right)=0.8$. Then:

$\left|\mu_{A}\left(x_{i}\right)\right|=\sqrt{|(1.8)(-0.2)|}=\sqrt{0.36}=0.6$.

Thus, $\mu_{A}\left(x_{i}\right)=0.6$. Hence, $\left(\mu_{A}\left(x_{i}\right)\right)^{2}+\left(v_{A}\left(x_{i}\right)\right)^{2}=1$ implies $\pi_{A}\left(x_{i}\right)=0$.

Definition 3.2 [19] Let $A \in \operatorname{PFS}(X)$. Then, the complement of $A$ denoted by $A^{c}$ is defined as follows:

$A^{c}=\left\{\left\langle x, v_{A}(x), \mu_{A}(x)\right\rangle \mid x \in X\right\}$.

Remark 3.1 It is noticed that $\left(A^{c}\right)^{c}=A$. This shows the validity of complementary law in PFS.

Definition 3.3 [19] Let $A, B \in \operatorname{PFS}(X)$. Then, the following define union and intersection of $A$ and $B$ :

(i) $A \cup B=\left\{\left\langle x, \max \left(\mu_{A}(x), \mu_{B}(x)\right), \min \left(v_{A}(x), v_{B}(x)\right)\right\rangle \mid\right.$ $x \in X\}$.

(ii) $A \cap B=\left\{\left\langle x, \min \left(\mu_{A}(x), \mu_{B}(x)\right), \max \left(v_{A}(x), v_{B}(x)\right)\right\rangle \mid\right.$ $x \in X\}$.
Definition 3.4 [19] Let $A, B \in \operatorname{PFS}(X)$. Then, the sum of $A$ and $B$ is defined as follows:

$$
\begin{aligned}
& A \oplus B=\left\{\left\langlex, \sqrt{\left(\mu_{A}(x)\right)^{2}+\left(\mu_{B}(x)\right)^{2}-\left(\mu_{A}(x)\right)^{2}\left(\mu_{B}(x)\right)^{2}},\right.\right. \\
& \left.\left.v_{A}(x) v_{B}(x)\right\rangle \mid x \in X\right\},
\end{aligned}
$$

and the product of $A$ and $B$ is defined as follows:

$A \otimes B=\left\{\left\langle x, \mu_{A}(x) \mu_{B}(x)\right.\right.$,

$$
\left.\left.\sqrt{\left(v_{A}(x)\right)^{2}+\left(v_{B}(x)\right)^{2}-\left(v_{A}(x)\right)^{2}\left(v_{B}(x)\right)^{2}}\right\rangle \mid x \in X\right\} .
$$

Remark 3.2 Let $A, B, C \in \operatorname{PFS}(X)$. Then, the following properties hold:

(a) Idempotent:
(i) $A \cap A=A$
(ii) $A \cup A=A$
(iii) $A \oplus A \neq A$
(iv) $A \otimes A \neq A$.

(b) Commutativity:
(i) $A \cap B=B \cap A$
(ii) $A \cup B=B \cup A$
(iii) $A \oplus B=B \oplus A$
(iv) $A \otimes B=B \otimes A$.

(c) Associativity:
(i) $A \cap(B \cap C)=(A \cap B) \cap C$
(ii) $A \cup(B \cup C)=(A \cup B) \cup C$
(iii) $A \oplus(B \oplus C)=(A \oplus B) \oplus C$
(iv) $A \otimes(B \otimes C)=(A \otimes B) \otimes C$.

(d) Distributivity:

(i) $A \cap(B \cup C)=(A \cap B) \cup(A \cap C)$

(ii) $A \cup(B \cap C)=(A \cup B) \cap(A \cup C)$

(iii) $A \oplus(B \cup C)=(A \oplus B) \cup(A \oplus C)$

(iv) $A \oplus(B \cap C)=(A \oplus B) \cap(A \oplus C)$

(v) $A \otimes(B \cup C)=(A \otimes B) \cup(A \otimes C)$

(vi) $A \otimes(B \cap C)=(A \otimes B) \cap(A \otimes C)$.

(e) DeMorgan's laws;

(i) $(A \cap B)^{c}=A^{c} \cup B^{c}$

(ii) $(A \cup B)^{c}=A^{c} \cap B^{c}$

(iii) $(A \oplus B)^{c}=A^{c} \otimes B^{c}$

(iv) $(A \otimes B)^{c}=A^{c} \oplus B^{c}$.

Definition 3.5 [53] Let $A \in \operatorname{PFS}(X)$. Then, the score function, $s$, of $A$ is defined by $s(A)=\left(\mu_{A}(x)\right)^{2}-\left(v_{A}(x)\right)^{2}$, where $s(A) \in[-1,1]$. 
Definition 3.6 [53] Let $A \in \operatorname{PFS}(X)$. Then, the accuracy function, $a$, of $A$ is defined by $a(A)=\left(\mu_{A}(x)\right)^{2}+\left(v_{A}(x)\right)^{2}$ for $a(A) \in[0,1]$.

Example 3.3 Let $A \in \operatorname{PFS}(X)$. Suppose that $a(A)=0.6$ and $v_{A}(x)=0.7$. Then, $\mu_{A}(x)=0.3317, s(A)=-0.38$, and $\pi_{A}(x)=0.6325$.

In addition, suppose that $s(A)=-0.5$ and $a(A)=0.8$. Then, it follows that $\mu_{A}(x)=0.3873, v_{A}(x)=0.8062$, and $\pi_{A}(x)=0.4472$.

Theorem 3.2 Let $A \in \operatorname{PFS}(X)$. Then, the following hold $\forall x \in X$ :

(i) $s(A)=0 \Leftrightarrow \mu_{A}(x)=v_{A}(x)$.

(ii) $s(A)=1 \Leftrightarrow\left|v_{A}(x)\right|=\sqrt{\left|\left(1+\mu_{A}(x)\right)\left(1-\mu_{A}(x)\right)\right|}$.

(iii) $s(A)=-1 \Leftrightarrow \mu_{A}(x)=\sqrt{\left(v_{A}(x)+1\right)\left(v_{A}(x)-1\right)}$.

Proof (i) Suppose $s(A)=0$. Then, $\left(\mu_{A}(x)\right)^{2}=\left(v_{A}(x)\right)^{2} \Rightarrow$ $\mu_{A}(x)=v_{A}(x) \forall x \in X$.

Conversely, assume that $\mu_{A}(x)=v_{A}(x)$. It follows immediately that, $\forall x \in X,\left(\mu_{A}(x)\right)^{2}=\left(v_{A}(x)\right)^{2}$. Thus, $\left(\mu_{A}(x)\right)^{2}-\left(v_{A}(x)\right)^{2}=0$. Hence, $s(A)=0$.

(ii) Suppose $s(A)=1$. Then:

$$
\begin{aligned}
1 & -\left(\mu_{A}(x)\right)^{2}=-\left(v_{A}(x)\right)^{2} \\
& \Rightarrow\left(1+\mu_{A}(x)\right)\left(1-\mu_{A}(x)\right)=-\left(v_{A}(x)\right)^{2} \\
& \Rightarrow\left|\left(1+\mu_{A}(x)\right)\left(1-\mu_{A}(x)\right)\right|=\left|v_{A}(x)\right|^{2} \\
& \Rightarrow\left|v_{A}(x)\right|=\sqrt{\left|\left(1+\mu_{A}(x)\right)\left(1-\mu_{A}(x)\right)\right|}
\end{aligned}
$$

$\forall x \in X$.

Conversely, assume that $\left|v_{A}(x)\right|=$ $\sqrt{\left|\left(1+\mu_{A}(x)\right)\left(1-\mu_{A}(x)\right)\right|}$. Therefore, we get the following:

$$
\left|v_{A}(x)\right|^{2}=\sqrt{\left|1-\left(\mu_{A}(x)\right)^{2}\right|} \Rightarrow\left(v_{A}(x)\right)^{2}=1-\left(\mu_{A}(x)\right)^{2}
$$

or

$$
\left|v_{A}(x)\right|^{2}=\sqrt{\left|1-\left(\mu_{A}(x)\right)^{2}\right|} \Rightarrow-\left(v_{A}(x)\right)^{2}=1-\left(\mu_{A}(x)\right)^{2} .
$$

Take $-\left(v_{A}(x)\right)^{2}=1-\left(\mu_{A}(x)\right)^{2} \Rightarrow\left(\mu_{A}(x)\right)^{2}-\left(v_{A}(x)\right)^{2}=$ $1 \Rightarrow s(A)=1$.

(iii) Suppose that $s(A)=-1$. Then

$$
\begin{aligned}
& \left(v_{A}(x)\right)^{2}-1=\left(\mu_{A}(x)\right)^{2} \Rightarrow\left(v_{A}(x)-1\right)\left(v_{A}(x)+1\right) \\
& \quad=\left(\mu_{A}(x)\right)^{2} \Rightarrow \mu_{A}(x)=\sqrt{\left(v_{A}(x)-1\right)\left(v_{A}(x)+1\right) .}
\end{aligned}
$$

Conversely, suppose $\mu_{A}(x)=\sqrt{\left(v_{A}(x)-1\right)\left(v_{A}(x)+1\right)}$. Then

$$
\begin{aligned}
\left(\mu_{A}(x)\right)^{2}=\left(v_{A}(x)\right)^{2}-1 & \Rightarrow\left(\mu_{A}(x)\right)^{2}-\left(v_{A}(x)\right)^{2}=-1 \\
& \Rightarrow s(A)=-1 .
\end{aligned}
$$

Theorem 3.3 Let $A \in \operatorname{PFS}(X)$. Then, the following statements hold $\forall x \in X$ :

(i) $a(A)=1 \Leftrightarrow \pi_{A}(x)=0$.

(ii) $a(A)=0 \Leftrightarrow\left|\mu_{A}(x)\right|=\left|v_{A}(x)\right|$.

Proof (i) Suppose $a(A)=1$. Therefore, we have $\left(\mu_{A}(x)\right)^{2}+$ $\left(v_{A}(x)\right)^{2}=1$, that is, $\pi_{A}(x)=0$, since $\pi_{A}(x)=$ $\sqrt{1-\left[\left(\mu_{A}(x)\right)^{2}+\left(v_{A}(x)\right)^{2}\right]}$.

Conversely, assume that $\pi_{A}(x)=0$. Then, it follows that:

$\left(\mu_{A}(x)\right)^{2}+\left(v_{A}(x)\right)^{2}=1 \Rightarrow a(A)=1$.

(ii) Suppose $a(A)=0$. Then, $\left(\mu_{A}(x)\right)^{2}=-\left(v_{A}(x)\right)^{2}$ or $\left(v_{A}(x)\right)^{2}=-\left(\mu_{A}(x)\right)^{2} \Leftrightarrow\left|\mu_{A}(x)\right|^{2}=\left|v_{A}(x)\right|^{2} \Leftrightarrow$ $\left|\mu_{A}(x)\right|=\left|v_{A}(x)\right|$.

Definition 3.7 Let $A, B \in \operatorname{PFS}(X)$. Then, $A=B \Leftrightarrow$ $\mu_{A}(x)=\mu_{B}(x)$ and $v_{A}(x)=v_{B}(x) \forall x \in X$, and $A \subseteq B$ $\Leftrightarrow \mu_{A}(x) \leq \mu_{B}(x)$ and $v_{A}(x) \geq v_{B}(x)\left(\right.$ or $\left.v_{A}(x) \leq v_{B}(x)\right)$ $\forall x \in X$. We say $A \subset B \Leftrightarrow A \subseteq B$ and $A \neq B$.

Definition 3.8 Let $A, B \in \operatorname{PFS}(X)$. Then, $A$ and $B$ are comparable to each other if $A \subseteq B$ and $B \subseteq A$.

We state the following theorems without prove because of their straightforwardness.

Theorem 3.4 Let $A, B \in \operatorname{PFS}(X)$. Then, the following statements hold:

(i) $s(A)=s(B) \Leftrightarrow A=B$.

(ii) $s(A) \leq s(B) \Leftrightarrow A \subseteq B$.

(iii) $s(A)<s(B) \Leftrightarrow A \subseteq B$ and $A \neq B$.

Theorem 3.5 Let $A, B \in \operatorname{PFS}(X)$. Then, the following hold:

(i) $a(A)=a(B) \Leftrightarrow A=B$.

(ii) $a(A) \leq a(B) \Leftrightarrow A \subseteq B$.

(iii) $a(A)<a(B) \Leftrightarrow A \subseteq B$ and $A \neq B$.

\section{Pythagorean fuzzy relation}

In this section, we propose Pythagorean fuzzy relation as an extension of both fuzzy relation and intuitionistic fuzzy relation $[8,52]$. The notions of extension principle for fuzzy sets $[54,55]$ and intuitionistic fuzzy set [56], respectively, are paramount to Pythagorean fuzzy relation. In what follows, we define the extension principle for Pythagorean fuzzy sets.

Definition 4.1 Let $X$ and $Y$ be sets and let $f$ be a function from $X$ to $Y$. Suppose that $A$ and $B$ are Pythagorean fuzzy sets of $X$ and $Y$, respectively. Then: 
(i) the image of $A$ under $f$, denoted by $f(A)$, is a Pythagorean fuzzy set of $Y$ defined by the following:

$\mu_{f(A)}(y)= \begin{cases}\bigvee_{x \in f^{-1}(y)} \mu_{A}(x), & f^{-1}(y) \neq \varnothing \\ 0, & \text { otherwise }\end{cases}$

and

$v_{f(A)}(y)= \begin{cases}\bigwedge_{x \in f^{-1}(y)} v_{A}(x), & f^{-1}(y) \neq \varnothing \\ 1, & \text { otherwise }\end{cases}$

for each $y \in Y$.

(ii) the inverse image of $B$ under $f$, denoted by $f^{-1}(B)$, is a Pythagorean fuzzy set of $X$ defined by the following:

$$
\begin{gathered}
\mu_{f^{-1}(B)}(x)=\mu_{B}(f(x)) \quad \text { and } \\
v_{f^{-1}(B)}(x)=v_{B}(f(x)) \forall x \in X .
\end{gathered}
$$

Definition 4.2 Let $X$ and $Y$ be two nonempty sets. A Pythagorean fuzzy relation (PFR), $R$, from $X$ to $Y$ is a PFS of $X \times Y$ characterized by the membership function, $\mu_{R}$ and nonmembership function, $v_{R}$. A PF relation or PFR from $X$ to $Y$ is denoted by $R(X \rightarrow Y)$.

Definition 4.3 Let $A \in \operatorname{PFS}(X)$. Then, the max-min-max composition of $R(X \rightarrow Y)$ with $A$ is a PFS $B$ of $Y$ denoted by $B=R \circ A$, such that its membership and nonmembership functions are defined by the following:

$\mu_{B}(y)=\bigvee_{x}\left(\min \left[\mu_{A}(x), \mu_{R}(x, y)\right]\right)$

and

$v_{B}(y)=\bigwedge_{x}\left(\max \left[v_{A}(x), v_{R}(x, y)\right]\right)$

$\forall x \in X$ and $y \in Y$, where $\bigvee=$ maximum, $\bigwedge=$ minimum.

Definition 4.4 Let $Q(X \rightarrow Y)$ and $R(Y \rightarrow Z)$ be two PFRs. Then, the max-min-max composition $R \circ Q$ is a PFR from $X$ to $Z$, such that its membership and nonmembership functions are defined by the following:

$\mu_{R \circ Q}(x, z)=\bigvee_{y}\left(\min \left[\mu_{Q}(x, y), \mu_{R}(y, z)\right]\right)$

and

$v_{R \circ Q}(x, z)=\bigwedge_{y}\left(\max \left[v_{Q}(x, y), v_{R}(y, z)\right]\right)$

$\forall(x, z) \in X \times Z$ and $\forall y \in Y$.
Remark 4.1 From Definitions 4.3 and 4.4, the max-min-max composition $B$ or $R \circ Q$ is calculated by the following:

$B=\mu_{B}(y)-v_{B}(y) \pi_{B}(y)$

$\forall y \in Y$ or

$R \circ Q=\mu_{R \circ Q}(x, z)-v_{R \circ Q}(x, z) \pi_{R \circ Q}(x, z)$

$\forall(x, z) \in X \times Z$.

Proposition 4.1 If $R$ and $S$ are two PFRs on $X \times Y$ and $Y \times Z$, respectively. Then:

(i) $\left(R^{-1}\right)^{-1}=R$.

(ii) $(S \circ R)^{-1}=R^{-1} \circ S^{-1}$.

\section{Numerical examples}

Before applying this relation to career placements, we discuss the procedures of the approach step-wisely.

Example 4.1 Let $E, F \in \operatorname{PFS}(X)$ for $X=\left\{x_{1}, x_{2}, x_{3}\right\}$. Suppose that

$E=\left\{\left\langle\frac{0.6,0.2}{x_{1}}\right\rangle,\left\langle\frac{0.4,0.6}{x_{2}}\right\rangle,\left\langle\frac{0.5,0.3}{x_{3}}\right\rangle\right\}$

and

$F=\left\{\left\langle\frac{0.8,0.1}{x_{1}}\right\rangle,\left\langle\frac{0.7,0.3}{x_{2}}\right\rangle,\left\langle\frac{0.6,0.1}{x_{3}}\right\rangle\right\}$.

We find the composition $B$ using Definitions 4.3 and 4.4, respectively, as follows:

$\min \left[\mu_{R}\left(e_{i}, x_{j}\right), \mu_{S}\left(x_{j}, f_{k}\right)\right]=0.6,0.4,0.5$,

implying that

$\mu_{B}\left(e_{i}, f_{k}\right)=\bigvee_{x_{j} \in X}(0.6,0.4,0.5)=0.6$.

Again:

$\max \left[v_{R}\left(e_{i}, x_{j}\right), v_{S}\left(x_{j}, f_{k}\right)\right]=0.2,0.6,0.3$,

implying that

$v_{B}\left(e_{i}, f_{k}\right)=\bigwedge_{x_{j} \in X}(0.2,0.6,0.3)=0.2$.

Then

$B=0.6-(0.2 \times 0.7746)=0.4451$. 
Now, we consider a situation where the elements of PFSs are not equal.

Example 4.2 Let $G, H \in \operatorname{PFS}(X)$ for $X=\left\{x_{1}, x_{2}, x_{3}, x_{4}\right.$, $\left.x_{5}\right\}$. Suppose that

$G=\left\{\left\langle\frac{0.8,0.4}{x_{1}}\right\rangle,\left\langle\frac{0.5,0.7}{x_{2}}\right\rangle,\left\langle\frac{0.8,0.4}{x_{3}}\right\rangle,\left\langle\frac{0.7,0.2}{x_{5}}\right\rangle\right\}$

and

$H=\left\{\left\langle\frac{0.7,0.3}{x_{1}}\right\rangle,\left\langle\frac{0.4,0.7}{x_{3}}\right\rangle,\left\langle\frac{0.9,0.2}{x_{4}}\right\rangle\right\}$.

Before calculating the max-min-max composition, we rewrite the PFSs; thus:

$$
\begin{aligned}
G= & \left\{\left\langle\frac{0.8,0.4}{x_{1}}\right\rangle,\left\langle\frac{0.5,0.7}{x_{2}}\right\rangle,\left\langle\frac{0.8,0.4}{x_{3}}\right\rangle,\left\langle\frac{0.0,1.0}{x_{4}}\right\rangle,\right. \\
& \left.\left\langle\frac{0.7,0.2}{x_{5}}\right\rangle\right\}
\end{aligned}
$$

and

$$
\begin{aligned}
H= & \left\{\left\langle\frac{0.7,0.3}{x_{1}}\right\rangle,\left\langle\frac{0.0,1.0}{x_{2}}\right\rangle,\left\langle\frac{0.4,0.7}{x_{3}}\right\rangle,\left\langle\frac{0.9,0.2}{x_{4}}\right\rangle,\right. \\
& \left.\left\langle\frac{0.0,1.0}{x_{5}}\right\rangle\right\} .
\end{aligned}
$$

Now, we find $B$ as follows. Using Definitions 4.3 and 4.4, we get

$\min \left[\mu_{R}\left(g_{i}, x_{j}\right), \mu_{S}\left(x_{j}, h_{k}\right)\right]=0.7,0.0,0.4,0.0,0.0$,

implying that

$\mu_{B}\left(g_{i}, h_{k}\right)=\bigvee_{x_{j} \in X}(0.7,0.0,0.4,0.0,0.0)=0.7$

Again

$\max \left[v_{R}\left(g_{i}, x_{j}\right), v_{S}\left(x_{j}, h_{k}\right)\right]=0.4,1.0,0.7,1.0,1.0$,

implying that

$v_{B}\left(g_{i}, h_{k}\right)=\bigwedge_{x_{j} \in X}(0.4,0.7,0.7,0.2,0.2)=0.4$.

Thus

$B=0.7-(0.4 \times 0.5916)=0.4634$.
Application of max-min-max composition for Pythagorean fuzzy sets to career placements

We localize the idea of PFR as follows. Let

$S=\left\{s_{1}, \ldots, s_{l}\right\}, C=\left\{c_{1}, \ldots, c_{m}\right\}$ and $A=\left\{a_{1}, \ldots, a_{n}\right\}$

be finite set of subjects related to the courses, finite set of courses, and finite set of applicants, respectively.

Suppose we have two PFRs, $R(A \rightarrow S)$ and $U(S \rightarrow C)$, such that

$R=\left\{\left\langle(a, s), \mu_{R}(a, s), v_{R}(a, s)\right\rangle \mid(a, s) \in A \times S\right\}$

and

$U=\left\{\left\langle(s, c), \mu_{U}(s, c), v_{U}(s, c)\right\rangle \mid(s, c) \in S \times C\right\}$,

where $\mu_{R}(a, s)$ represents the degree to which the applicant, $a$, passes the related subject requirement, $s$, and $v_{R}(a, s)$ represents the degree to which the applicant, $a$ does not pass the related subject requirement, $s$. Similarly, $\mu_{U}(s, c)$ represents the degree to which the related subject requirement, $s$ determines the course, $c$, and $v_{U}(s, c)$ represents the degree to which the related subject requirement, $s$, does not determine the course, $c$.

The composition, $T$, of $R$ and $U$ is given as $T=R \circ$ $U$. This describes the state in which the applicants, $a_{i}$ with respect to the related subjects requirement, $s_{j}$ fit the courses, $c_{k}$. Thus:

$\mu_{T}\left(a_{i}, c_{k}\right)=\bigvee_{s_{j} \in S}\left\{\min \left[\mu_{R}\left(a_{i}, s_{j}\right), \mu_{U}\left(s_{j}, c_{k}\right)\right]\right\}$

and

$v_{T}\left(a_{i}, c_{k}\right)=\bigwedge_{s_{j} \in S}\left\{\max \left[v_{R}\left(a_{i}, s_{j}\right), v_{U}\left(s_{j}, c_{k}\right)\right]\right\}$

$\forall a_{i} \in A$ and $c_{k} \in C$, where $i, j$ and $k$ take values from $1, \ldots, n$.

The values of $\mu_{R \circ U}\left(a_{i}, c_{k}\right)$ and $v_{R \circ U}\left(a_{i}, c_{k}\right)$ of the composition $T=R \circ U$ are as follows (Table 4):

The career placement can be achieved if the value of $T$ is given by the following:

$T=\mu_{T}\left(a_{i}, c_{k}\right)-v_{T}\left(a_{i}, c_{k}\right) \pi_{T}\left(a_{i}, c_{k}\right)$,

as computed from $R$ and $U$ for the placements of $a_{i}$ into any $c_{k}$ with respect to $s_{j}$ is the greatest. 
Table $2 \quad R(A \rightarrow S)$

\begin{tabular}{lllllll}
\hline$R$ & English & Maths & Biology & Physics & Chemistry & Health \\
\hline Ada & $\langle 0.6,0.3\rangle$ & $\langle 0.5,0.4\rangle$ & $\langle 0.6,0.3\rangle$ & $\langle 0.5,0.3\rangle$ & $\langle 0.5,0.5\rangle$ & $\langle 0.6,0.2\rangle$ \\
Ene & $\langle 0.5,0.3\rangle$ & $\langle 0.6,0.3\rangle$ & $\langle 0.5,0.3\rangle$ & $\langle 0.4,0.5\rangle$ & $\langle 0.7,0.2\rangle$ & $\langle 0.7,0.1\rangle$ \\
Ehi & $\langle 0.7,0.3\rangle$ & $\langle 0.7,0.2\rangle$ & $\langle 0.7,0.3\rangle$ & $\langle 0.5,0.4\rangle$ & $\langle 0.4,0.5\rangle$ & $\langle 0.6,0.3\rangle$ \\
Ebo & $\langle 0.6,0.4\rangle$ & $\langle 0.8,0.2\rangle$ & $\langle 0.6,0.3\rangle$ & $\langle 0.6,0.3\rangle$ & $\langle 0.5,0.3\rangle$ & $\langle 0.7,0.2\rangle$ \\
Ela & $\langle 0.8,0.1\rangle$ & $\langle 0.7,0.2\rangle$ & $\langle 0.8,0.2\rangle$ & $\langle 0.7,0.1\rangle$ & $\langle 0.6,0.1\rangle$ & $\langle 0.8,0.1\rangle$ \\
\hline
\end{tabular}

Table $3 U(S \rightarrow C)$

\begin{tabular}{llllll}
\hline$U$ & Medicine & Pharmacy & Surgery & Anatomy & Physiology \\
\hline English & $\langle 0.8,0.1\rangle$ & $\langle 0.9,0.1\rangle$ & $\langle 0.5,0.4\rangle$ & $\langle 0.7,0.3\rangle$ & $\langle 0.8,0.2\rangle$ \\
Maths & $\langle 0.7,0.2\rangle$ & $\langle 0.8,0.1\rangle$ & $\langle 0.5,0.3\rangle$ & $\langle 0.5,0.4\rangle$ & $\langle 0.5,0.3\rangle$ \\
Biology & $\langle 0.9,0.1\rangle$ & $\langle 0.8,0.2\rangle$ & $\langle 0.9,0.1\rangle$ & $\langle 0.8,0.2\rangle$ & $\langle 0.9,0.1\rangle$ \\
Physics & $\langle 0.6,0.3\rangle$ & $\langle 0.5,0.2\rangle$ & $\langle 0.5,0.4\rangle$ & $\langle 0.6,0.3\rangle$ & $\langle 0.6,0.2\rangle$ \\
Chemistry & $\langle 0.8,0.2\rangle$ & $\langle 0.7,0.2\rangle$ & $\langle 0.7,0.3\rangle$ & $\langle 0.8,0.2\rangle$ & $\langle 0.7,0.2\rangle$ \\
Health & $\langle 0.8,0.1\rangle$ & $\langle 0.8,0.2\rangle$ & $\langle 0.7,0.3\rangle$ & $\langle 0.9,0.1\rangle$ & $\langle 0.8,0.2\rangle$ \\
\hline
\end{tabular}

Table $4 \mu_{R \circ U}\left(a_{i}, c_{k}\right)$ and $v_{R \circ U}\left(a_{i}, c_{k}\right)$

\begin{tabular}{llllll}
\hline$\mu, v$ & Medicine & Pharmacy & Surgery & Anatomy & Physiology \\
\hline Ada & $\langle 0.6,0.2\rangle$ & $\langle 0.6,0.2\rangle$ & $\langle 0.6,0.3\rangle$ & $\langle 0.6,0.2\rangle$ & $\langle 0.6,0.2\rangle$ \\
Ene & $\langle 0.7,0.1\rangle$ & $\langle 0.7,0.1\rangle$ & $\langle 0.7,0.3\rangle$ & $\langle 0.7,0.1\rangle$ & $\langle 0.7,0.2\rangle$ \\
Ehi & $\langle 0.7,0.2\rangle$ & $\langle 0.7,0.2\rangle$ & $\langle 0.7,0.3\rangle$ & $\langle 0.7,0.3\rangle$ & $\langle 0.7,0.3\rangle$ \\
Ebo & $\langle 0.7,0.2\rangle$ & $\langle 0.8,0.2\rangle$ & $\langle 0.7,0.3\rangle$ & $\langle 0.7,0.2\rangle$ & $\langle 0.7,0.2\rangle$ \\
Ela & $\langle 0.8,0.1\rangle$ & $\langle 0.8,0.1\rangle$ & $\langle 0.8,0.2\rangle$ & $\langle 0.8,0.1\rangle$ & $\langle 0.8,0.1\rangle$ \\
\hline
\end{tabular}

\section{Application example}

We apply this method using a hypothetical case with a quasireal data. Let

$A=\{$ Ada, Ene, Ehi, Ebo, Ela $\}$

be the set of applicants for the course placements;

$C=\{$ medicine, pharmacy, surgery, anatomy, physiology $\}$

be the set of courses the applicants are vying for;

$S=\{$ English Lang., Maths, Biology, Physics, Chemistry, Health Sci.\}

be the set of related subjects requirement to the set of courses.

Suppose the PFR, $R(A \rightarrow S)$ is given in Table 2. These data in PF values are assumably gotten after the aforementioned applicants sat for a multiple choice qualification examination on the itemized subjects within a stipulated time.

The first entry is the membership value, $\mu$, representing the Pythagorean fuzzy value of the marks allocated to the questions that the applicants answered, and the second entry is the nonmembership value, $v$, representing the Pythagorean fuzzy value of the marks allocated to the questions failed.
Again, the PFR, $U(S \rightarrow C)$, is the institution benchmark for admission into the aforesaid courses in PF values. The data are in Table 3.

We now find the indeterminate degree, $\pi$, for each applicants against the courses. The value of $\pi$ is the marks loss due to the hesitation in answering within a stipulated time. It is gotten by $\sqrt{1-\left[\mu^{2}+v^{2}\right]}$. The values of $\pi$ enable us to calculate $T$.

\section{Decision-making on course/career placements}

We present two forms of decision-making, viz: (1) horizontal decision with respect to applicant against courses, and (2) vertical decision with respect to course against applicants. Decisions are made based on the greatest value of relation between applicants and courses.

In accordance to the institution's benchmark for admission and applicants' performance in the qualification examination within a stipulated time, we make the following decisions from Table 5.

Horizontal decision This decision-making is based on relation/suitability of the applicants to the list of courses. 
Table $5 \quad T=\mu_{T}-v_{T} \pi_{T}$

\begin{tabular}{llllll}
\hline$T$ & Medicine & Pharmacy & Surgery & Anatomy & Physiology \\
\hline Ada & 0.4451 & 0.4451 & 0.3775 & 0.4451 & 0.4451 \\
Ene & 0.6293 & 0.6293 & 0.5056 & 0.6293 & 0.5629 \\
Ehi & 0.5629 & 0.5629 & 0.5056 & 0.5056 & 0.5056 \\
Ebo & 0.5629 & 0.6869 & 0.5056 & 0.5629 & 0.5629 \\
Ela & 0.7408 & 0.7408 & 0.6869 & 0.7408 & 0.7408 \\
\hline
\end{tabular}

Ada is suitable to study any of medicine, pharmacy, anatomy, and physiology.

Ene is suitable to study any of medicine, pharmacy, and anatomy.

Ehi is suitable to study either medicine or pharmacy.

Ebo is suitable to study only pharmacy.

Ela is more suitable to study any of the courses; Ada is suitable to study.

Vertical decision Vertical decision is centered on relation/suitability and competition. It is noticed that:

medicine is suitable to be studied by Ela (0.7408) and Ene (0.6293);

pharmacy is suitable to be studied by Ela (0.7408) and Ebo (0.6869);

surgery is suitable to be studied by Ela (0.6869) and any of Ebo (0.5056), Ehi (0.5056), and Ene (0.5056);

anatomy is suitable to be studied by Ela (0.7408) and Ene (0.6293);

physiology is suitable to be studied by Ela (0.7408), Ebo (0.5629), and Ene (0.5629).

\section{Observations}

The following observations are deducible from the decisions above.

(i) Vertical decision is the most reliable, because it considers suitability/relation and mental ability, and it is competitive.

(ii) Ela is the most brilliant applicant with the ability to study all the courses ahead of the other applicants in the order: medicine (0.7408), pharmacy (0.7408), anatomy (0.7408), physiology (0.7408), and surgery (0.6869).

(iii) Ene has the ability to study the following courses in the order: medicine (0.6293), anatomy (0.6293), physiology (0.5629), and surgery (0.5056).

(iv) Ebo has the ability to study the following courses in the order: pharmacy (0.6869), physiology (0.5629), and surgery (0.5056). (v) Ehi has the ability to study only surgery (0.5056) with the same ability as Ene and Ebo.

(vi) Ada is not suitable to study any of the courses in a competitive environment.

From the aforesaid discussion, it is meet to assert that the max-min-max composition approach explored in this study is very suitable and decisive, especially in a critical decisionmaking problem like career placements. In fact, without this approach, this exercise would have been compromised with a consequent effect on performance and efficiency.

\section{Conclusion}

The notion of Pythagorean fuzzy sets is a relatively novel mathematical framework in the fuzzy family with higher ability to cope imprecision imbedded in decision-making. In this paper, we have studied the concept of PFS more expressly with relevant illustrations, where necessary. Some important remarks were drawn which differentiated PFSs from IFSs. It was observed that every IFS is PFS, but the converse is not always true. Some theorems on PFSs were deduced and proved, especially on the ideas of score and accuracy functions. We also extended the concept of relation to PFSs, called $\mathrm{PF}$ relation (or PFR), and illustrated the concept using numerical examples. Finally, an application of PFSs was explored on course placements based on academic performance using the proposed composition relation.

The max-min-max composition introduced in this paper could be used as a viable tool in applying PFSs to MCDM problems, MADM problems, pattern recognition problems, etc. Notwithstanding, it is suggestible to consider this approach from object-oriented perspective for quick output in further research. In addition, some theoretic notions of PFSs and PF relation could still be exploited, and the concept of PFSs could be applied to solve more real-life problems imbedded with imprecision.

Open Access This article is distributed under the terms of the Creative Commons Attribution 4.0 International License (http://creativecomm ons.org/licenses/by/4.0/), which permits unrestricted use, distribution, and reproduction in any medium, provided you give appropriate credit to the original author(s) and the source, provide a link to the Creative Commons license, and indicate if changes were made.

\section{References}

1. Zadeh LA (1965) Fuzzy sets. Inf Control 8:338-353

2. Atanassov KT (1983) Intuitionistic fuzzy sets. VII ITKR's Session, Sofia

3. Atanassov KT (1986) Intuitionistic fuzzy sets. Fuzzy Sets Syst 20:87-96 
4. Atanassov KT (1999) Intuitionistic fuzzy sets: theory and applications. Physica, Heidelberg

5. Atanassov KT (2012) On intuitionistic fuzzy sets theory. Springer, Berlin

6. Atanassov KT (1989) Geometrical interpretation of the elements of the intuitionistic fuzzy objects. Preprint IM-MFAIS-1-89, Sofia

7. Davvaz B, Sadrabadi EH (2016) An application of intuitionistic fuzzy sets in medicine. Int J Biomath 9(3):1650037

8. De SK, Biswas R, Roy AR (2001) An application of intuitionistic fuzzy sets in medical diagnosis. Fuzzy Sets Syst 117(2):209-213

9. Ejegwa PA, Modom ES (2015) Diagnosis of viral hepatitis using new distance measure of intuitionistic fuzzy sets. Int J Fuzzy Math Arch 8(1):1-7

10. Szmidt E, Kacprzyk J (2001) Intuitionistic fuzzy sets in some medical applications. Note IFS 7(4):58-64

11. Szmidt E, Kacprzyk J (2004) Medical diagnostic reasoning using a similarity measure for intuitionistic fuzzy sets. Note IFS 10(4):6169

12. Ejegwa PA, Akubo AJ, Joshua OM (2014) Intuitionistic fuzzzy sets in career determination. J Info Comput Sci 9(4):285-288

13. Ejegwa PA (2015) Intuitionistic fuzzy sets approach in appointment of positions in an organization via max-min-max rule. Glob J Sci Front Res F Math Decis Sci 15(6):1-6

14. Garg H, Singh S (2018) A novel triangular interval type-2 intuitionistic fuzzy set and their aggregation operators. Iran J Fuzzy Syst 15(5):69-93

15. Garg H, Kumar K (2018) An advance study on the similarity measures of intuitionistic fuzzy sets based on the set pair analysis theory and their application in decision making. Soft Comput 22(15):4959-4970

16. Garg H, Kumar K (2018) Distance measures for connection number sets based on set pair analysis and its applications to decisionmaking process. Appl Intell 48(10):3346-3359

17. Yager RR (2013) Pythagorean membership grades in multicriteria decision making. In: Technical report MII-3301. Machine Intelligence Institute, Iona College, New Rochelle

18. Yager RR (2013) Pythagorean fuzzy subsets. In: Proceedings of the joint IFSA world congress NAFIPS annual meeting, pp 57-61

19. Yager RR (2014) Pythagorean membership grades in multicriteria decision making. IEEE Trans Fuzzy Syst 22(4):958-965

20. Garg H (2017) A new improved score function of an interval-valued Pythagorean fuzzy set based TOPSIS method. Int J Uncertain Quantif 7(5):463-474

21. Peng X, Yang Y (2015) Some results for Pythagorean fuzzy sets. Int J Intell Syst 30:1133-1160

22. Peng X, Selvachandran G (2017) Pythagorean fuzzy set: state of the art and future directions. Artif Intell Rev. https://doi.org/10. 1007/s10462-017-9596-9

23. Beliakov G, James S (2014) Averaging aggregation functions for preferences expressed as Pythagorean membership grades and fuzzy orthopairs. In: Proceedings of the IEEE international conference on fuzzy systems (FUZZ-IEEE), pp 298-305

24. Dick S, Yager RR, Yazdanbakhsh O (2016) On Pythagorean and complex fuzzy set operations. IEEE Trans Fuzzy Syst 24(5):10091021

25. Gou XJ, Xu ZS, Ren PJ (2016) The properties of continuous Pyhagorean fuzzy information. Int J Intell Syst 31(5):401-424

26. He X, Du Y, Liu W (2016) Pythagorean fuzzy power average operators. Fuzzy Syst Math 30(6):116-124

27. Ejegwa PA (2018) Distance and similarity measures of Pythagorean fuzzy sets. Granul Comput. https://doi.org/10.1007/s41066-01800149-z

28. Rahman K, Abdullah S, Shakeel M, Khan MSA, Ullah M (2017) Interval-valued Pythagorean fuzzy geometric aggregation operators and their application to group decision making problem. Cogent Math 4:1-19. https://doi.org/10.1080/23311835. 2017.1338638

29. Perez-Dominguez L, Rodriguez-Picon LA, Alvarado-Iniesta A, Cruz DL, Xu Z (2018) MOORA under Pythagorean fuzzy sets for multiple criteria decision making. Complex. https://doi.org/10. $1155 / 2018 / 2602376$

30. Liang D, Xu Z (2017) The New extension of TOPSIS method for multiple criteria decision making with hesitant Pythagorean fuzzy sets. Appl Soft Comput 60:167-179

31. Mohagheghi V, Vahdani B Mousavi SM (2017) Enhancing decision-making flexibility by introducing a new last aggregation evaluating approach based on multi-criteria group decision making and Pythagorean fuzzy sets. Appl Soft Comput 61:527-535

32. Rahman K, Ali A, Abdullah S, Amin F (2018) Approaches to multiattribute group decision making based on induced interval-valued Pythagorean fuzzy Einstein aggregation operator. New Math Nat Comput 14(3):343-361

33. Garg H (2018) New Logarithmic operational laws and their aggregation operators for Pythagorean fuzzy set and their applications. Int J Intell Syst. https://doi.org/10.1002/int.22043

34. Garg H (2018) Generalized Pythagorean fuzzy geometric interactive aggregation operators using Einstein operations and their application to decision making. J Exp Theor Artif Intell 30(6):763794

35. Garg H (2018) A linear programming method based on an improved score function for interval-valued Pythagorean fuzzy numbers and its application to decision-making. Int J Uncertain Fuzziness Knowl Based Syst 29(1):67-80

36. Garg H (2018) Some methods for strategic decision-making problems with immediate probabilities in Pythagorean fuzzy environment. Int J Intell Syst 33(4):687-712

37. Garg H (2018) A new exponential operational laws and their aggregation operators of interval-valued Pythagorean fuzzy information. Int J Intell Syst 33(3):653-683

38. Gao H, Wei GW (2018) Multiple attribute decision making based on interval-valued Pythagorean fuzzy uncertain linguistic aggregation operators. Int J Knowl Based Intell Eng Syst 22:59-81

39. Rahman K, Abdullah S (2018) Generalized Interval-valued Pythagorean fuzzy aggregation operators and their application to group decision making. Granul Comput. https://doi.org/10.1007/ s41066-018-0082-9

40. Rahman K, Abdullah S, Ali A (2018) Some induced aggregation operators based on interval-valued Pythagorean fuzzy numbers. Granul Comput. https://doi.org/10.1007/s41066-018-0091-8

41. Khan MSA, Abdullah S, Ali A, Amin F (2018) Pythagorean fuzzy prioritized aggregation operators and their application to multiattribute group decision making. Granul Comput. https://doi.org/10. 1007/s41066-018-0093-6

42. Khan MSA, Abdullah S, Ali A, Amin F (2018) An extension of VIKOR method for multiattribute decision making under Pythagorean hesitant fuzzy setting. Granul Comput. https://doi. org/10.1007/s41066-018-0102-9

43. Du YQ, Hou F, Zafar W, Yu Q, Zhai Y (2017) A novel method for multiattribute decision making with interval-valued Pythagorean fuzzy linguistic information. Int J Intell Syst 32(10):1085-1112

44. Garg H (2018) Linguistic Pythagorean fuzzy sets and its applications in multiattribute decision making process. Int J Intell Syst 33(6):1234-1263

45. Garg H (2016) A new generalized Pythagorean fuzzy information aggregation using Einstein operations and its application to decision making. Int J Intell Syst 31(9):886-920

46. Garg H (2016) A novel accuracy function under inter-valued Pythagorean fuzzy environment for solving multicriteria decision making problem. J Intell Fuzzy Syst 31(1):529-540 
47. Garg H (2016) A novel correlation coefficients between Pythagorean fuzzy sets and its applications to decision making processes. Int J Intell Syst 31(12):1234-1252

48. Garg H (2017) Generalized Pythagorean fuzzy geometric aggregation operators using Einstein $t$-norm and $t$-conorm fo multicriteria decision making process. Int J Intell Syst 32(6):597-630

49. Hadi-Venchen A, Mirjaberi M (2014) Fuzzy inferior ratio method for multiple attribue decision making problems. Inf Sci 277:263272

50. Yager RR, Abbasov AM (2013) Pythagorean membership grades, complex numbers and decision making. Int J Intell Syst 28(5):436452

51. Yager RR (2016) Properties and applications of Pythagoean fuzzy sets. Springer, Berlin

52. Sanchez E (1976) Resolution of composition fuzzy relation equations. Inf Control 30:38-48

53. Zhang XL, Xu ZS (2014) Extension of TOPSIS to multi-criteria decision making with Pythagorean fuzzy sets. Int J Intell Syst 29:1061-1078
54. Zadeh LA (1975) The concept of linguistic variable and its application to approximate reasoning. Inf Control 8:199-249

55. Nguyen HT (1978) A note on the extension principle for fuzzy sets. J Math Anal Appl 64:369-380

56. Atanassova L (2007) On intuitionistic fuzzy version of $L$. Zadeh's extension principle. Note IFS 13(3):33-36

Publisher's Note Springer Nature remains neutral with regard to jurisdictional claims in published maps and institutional affiliations. 